ENTOMOLOGY

\title{
Diversity, Distribution and Varietal Preference of Fruit Fly, Bactrocera spp. in Mango Ecosystem
}

\author{
S. Vignesh" ${ }^{* 1}$ M. Chandrasekaran ${ }^{2}$, V. Ambethgar ${ }^{3}$ and S. Jeeva ${ }^{4}$
}

${ }^{1}$ Department of Plant Protection, Anbil Dharmalingam Agricultural College and Research Institute, Tamil Nadu Agricultural University, Tiruchirappalli - 620 027, Tamil Nadu, India

${ }^{2}$ Department of Plant Protection, Horticultural College and Research Institute for Women, Tamil Nadu Agricultural University, Tiruchirappalli - 620 027, Tamil Nadu, India

${ }^{3}$ Director, Tamil Nadu Rice Research Institute, Tamil Nadu Agricultural University, Aduthurai - 612101, Tamil Nadu, India

${ }^{4}$ Department of Fruit Science, Horticultural College and Research Institute for Women, Tamil Nadu Agricultural University, Tiruchirappalli - 620 027, Tamil Nadu, India

"Corresponding author: vigneshsivakumaran@gmail.com (ORCID ID: 0000-0002-0657-1459)

Paper No. 833

Received: 03-01-2020

Revised: 09-04-2020

Accepted: 22-05-2020

\begin{abstract}
Mango is the second major fruit crop cultivated in India, it is known as "King of fruits" owing to delicious quality of fruit with richness in vitamins and minerals and has a socio economic significance in international market. It is attacked by many insects and mite pests; the yield and quality aspects of the mango are highly inflicted by fruit flies and make it unmarketable and inconsumable. The varied agro climatic conditions prevailed in tropical and subtropical regions makes them to spread all over the country. The documented information in a particular area on the population dynamics of fruit flies is essential to take preventive measures and to implement suitable management strategies. Keeping this in mind, the experiment on its species diversity, distribution pattern with its varietal preference of fruit flies in mango ecosystem was undertaken by using methyl eugenol based parapheromone traps during 2017-18 at Anbil Dharmalingam Agricultural College and Research Institute, Tamil Nadu Agricultural University, Tiruchirappalli. The major diversity of species registered in mango ecosystem is viz., Bactrocera caryeae (Kapoor), B.dorsalis (Hendel) and B.correcta (Bezzi). The activity of fruit fly is maximum in the month of August and September with the mean catch ranges from 27.00 to 57.00 flies/ trap/week. The poor activity of fruit flies in mango orchards was registered in the month of November to February with the least trapped population of $<3.0 \mathrm{flies} /$ trap/week. Considering the varietal preference, the prevalence of B.correcta both in rumani and PKM 1 varieties is comparatively less when compared with the B.dorsalis and B.caryeae. The correlation analysis results revealed that, the fruit fly incidence is positively correlated with maximum, minimum temperature and negatively correlated with morning, evening relative humidity $(\mathrm{RH})$ and rainfall.

\section{Highlights}

0 In India, the fruit fly Bactrocera sp. is most prevalent in mango and cause economic loss.

( The problem of fruit flies in a mango orchard can be easily mitigated by proper periodical assessment and using parapheromone traps.

0 To limit proliferation, it is essential to control the fly population at the beginning of the season.
\end{abstract}

Keywords: Fruit fly, Bactrocera spp., Mango, Diversity, Distribution, Varietal preference

Mango, Mangifera indica L. (Anacardiaceae) is known as the king of fruits for its flavor, delicious taste and high nutritive value. It continues to dominate the Indian fruit basket by contributing
34.9 per cent to total fruit area and 20.7 per cent to total fruit production with the productivity of 8.7 MT/ha (Singh et al. 2018). Mango being a seasonal crop, the pest scenario also changes with the season. 
Flies of the genus Bactrocera (Diptera: Tephritidae) are one among the most devastating insect pests to mango fruit cultivations in both the tropical and subtropical regions (Tan and Serit 1994) and this fly is especially serious in south India (Verghese et al. 2006). The fruit flies also known as "Peacock flies" due to its unique architect wings, these minute flies can cause yield loss up to $31 \%$ with an annual mean of $16 \%$ in mango (Verghese and Jayanthi 2001). Besides causing the direct damage to fruit, it will also causes indirect loss by affecting the export of fruits (Siddiq et al. 2017). In mango ecosystem, they show remarkable changes in its behavioral and ecological characteristics and express it in diversity, pattern of distribution and preference towards the varieties. The documentation on the population dynamics of fruit fly in mango ecosystem provides both opportunities and challenges for planning and preceding the timely management practices (Veeresh 1989). The influence of external weather factors on the population of fruit flies and species diversity must be carefully recorded for selecting and implementing the suitable species specific attractant to bring the effective management in the subsequent years. Keeping this in mind, the present investigation sought to study the species diversity, seasonal distribution pattern and to assess its varietal preference in mixed mango ecosystem.

\section{MATERIALS AND METHODS}

The experiment was carried out at Anbil Dharmalingam Agricultural College and Research Institute, Tamil Nadu Agricultural University, Tiruchirappalli. The prediction of species diversity, distribution pattern throughout the year, seasonal abundance and varietal preference of fruit flies in mango ecosystem was made during 2017-18 in the mango orchard of Horticultural College and Research Institute for women and in the farmer's mango garden located at Podhavur village of Tiruchirappalli District located between $10^{\circ} 45^{\prime} \mathrm{N}$ latitude and $78^{\circ} 36^{\prime} \mathrm{E}$ longitude at an altitude of $85 \mathrm{~m}$ above the Mean Sea Level. The cylindrical jar type trap of about $15 \mathrm{~cm}$ height and $10 \mathrm{~cm}$ diameter with two holes of size about $5 \mathrm{~cm}$ diameter in the sidewall, which act as entry point for fruit fly will be taken for monitoring the fruit fly activity in mango orchards. A wooden dispenser of size $4 \times 2 \times 1 \mathrm{~cm}$ charged with methyl eugenol is hanged at the top of the trap using an iron wire act as an attractant for fruit fly. Top of the trap is entirely sealed and the perforated bottom is screwed with the jar trap. The perforations present in the bottom of the trap aids in drainage of the rain water. The traps were hanged in the mango trees at a height of $1.5 \mathrm{~m}$ above the ground level. The experiment was conducted from $21^{\text {st }}$ Standard Meteorological Week of 2017 to $20^{\text {th }}$ Standard meteorological week of 2018 for the period of 12 months. The fruit flies trapped were periodically monitored once in a week and to counteract the positional effect of traps its position will be changed once in a week during the observation. The observed parameters were subjected to relevant correlation analysis to assess the impact of varied weather factors on the population and spread of fruit flies.

\section{RESULTS AND DISCUSSION}

\section{Species diversity}

The fruit flies trapped were periodically monitored once in a week and the trapped adult males were carefully collected and identified at species level by following the catalogue of Agarwal and Sueyoshi (2005). The categorization shown that the major species of fruit flies prevailing in the mango ecosystem is B.caryeae, B.dorsalis and B.correcta. Among these three species identified, diversity of all the three species were more prevalence in rumani varietal block with the maximum trapping population of 120 numbers of fruit flies per trap were recorded during the third week of August and it was followed by second week of September (68 flies/trap). Whereas in PKM 1 variety, the diversity of B.caryeae and B.dorsalis are more prevalent and registered the trapping population in the second week of August (46 flies/trap), when compared with B.correcta. The observations on B.correcta indicated that the population and feeding preference towards the variety rumani is more than the variety PKM 1. In general, irrespective of mango varieties and fruit fly species the least population of fruit flies $(<4$ No./trap) were trapped from second week of November to Fourth week of February (Fig.1\&2). The prevalence and pattern of occurrence of fruit fly throughout the year and its peak incidence observed during the month of August and September was also strengthened and supported by the previous 
report of Kumar et al. (2018) in different mango orchards of Western plain zone of Uttar Pradesh and Nair and Bhattacharjee (2017) in cucurbit ecosystem of varied districts of Tripura.

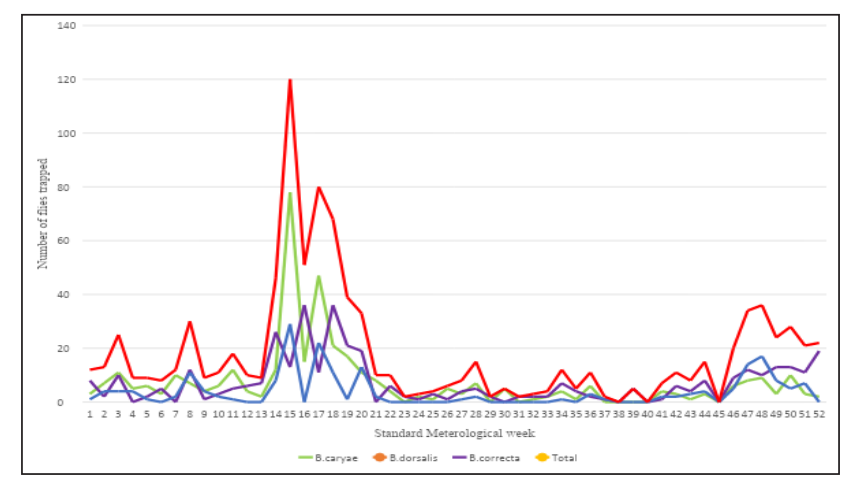

Fig. 1: Diversity and varietal preference of fruit flies in the Rumani variety of mango

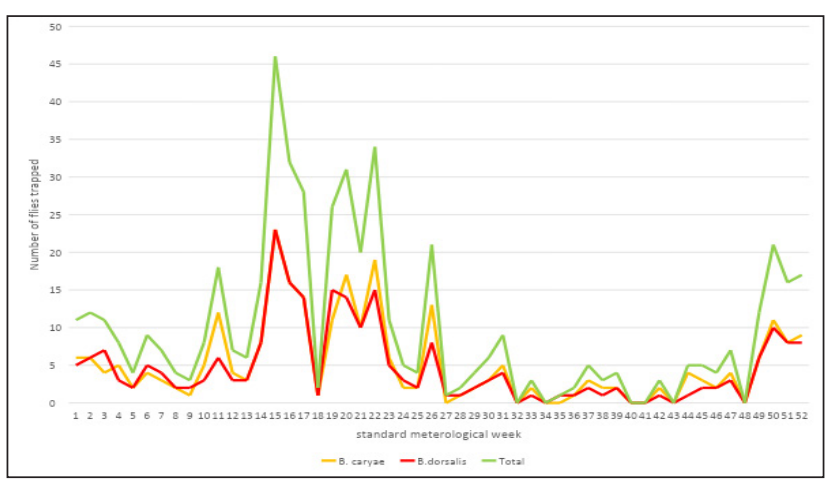

Fig. 2: Diversity and varietal preference of fruit flies in the PKM -1 variety of mango

\section{Distribution and Varietal preference}

The seasonal abundance and distribution pattern of fruit flies based on the trap catches in mango orchards indicates that activity of fruit fly is maximum in the months of April, August and September with the mean catches ranges from 24.50 to 57.50 flies/trap/week. The poor activity of fruit flies in mango orchards was registered in the month of December to February with the least trapped population of $<10$ flies/trap/week. The prevalence, abundance and distribution of all the three species of fruit flies were more in the months of April, August and September when compared with other months of the year. This finding was substantiated by the previous reports of Baloda et al. (2018) that the maximum population of B.dorsalis noticed during the month of August and minimum population in the month of January, in case of
B.zonata the maximum population was recorded in the month of July and minimum population was recorded in the month of December and January in guava.

In rumani variety of mango, considering the average population trapped per week; the species, B.caryeae and B. dorsalis was maximum in the month of August (26.75 and 20.50 flies/trap) followed by September (24.00 and 21.75 flies/trap) against the minimum number i.e. $<4$ flies/trap registered during October to February (Table 1). Considering the pattern of distribution of B. caryeae, it is clearly indicated that $B$. caryeae highly prefers the PKM 1 variety while comparing with B.dorsalis and its richness also equally distributed in throughout the year. The maximum number of $B$. caryeae was recorded during April (30.50 flies/trap) and it was followed by August (25.25 flies/trap) and September (19.75 flies/trap), whereas minimum population of $<$ 4 flies/trap was observed in December and February. The prevalence of B.dorsalis in PKM 1 block was only next to $B$. caryeae but it was also registered the peak trapped population in the month of August. This present findings of seasonal incidence of fruit flies in mango was in tune with the reports of Stanley et al. (2015) with respect to B. dorsalis at North west region of India and Khan and Naveed (2017) relevant with the species of $B$. zonata at Faisalabad, Pakistan. The diversity and distribution pattern of B.dorsalis recorded in the experimental period is in tune with the findings of Laskar and Chatterjee (2010) under tropical condition.

The occurrence of B.correcta in mango orchard is comparatively less when compared with the B.dorsalis and B.caryeae. In rumani, the weekly trapped population of B.correcta was very poor $(<10$ flies/trap) other than April and September (12 flies/ trap). In case of PKM - 1 , the prevalence of B.correcta was not noticed throughout the experimental period. In general, the maximum population of fruit fly trapped in the months of August, September and April when compared with the remaining months irrespective of species variations (Table 1). These observations on the activities of fruit flies in mango orchards are in consonance with the findings of Rattanapun et al. (2009). They also observed the similar trend of fruit fly activity throughout the year with the maximum population during July to October months. The earlier workers also 
Table 1: Diversity, seasonal incidence and varietal preference of fruit fly, Bactrocera spp. in the mango orchard $(2017-18)$

\begin{tabular}{|c|c|c|c|c|c|c|c|c|c|c|c|c|}
\hline \multirow{3}{*}{$\begin{array}{l}\text { Month } \\
\text { (2017-18) }\end{array}$} & \multicolumn{7}{|c|}{ Month wise Mean fruit fly population trapped / trap / week* (SMW) } & \multicolumn{5}{|c|}{$\begin{array}{l}\text { Mean Meteorological parameters/ } \\
\text { Month }\end{array}$} \\
\hline & \multicolumn{4}{|c|}{ Variety: Rumani } & \multicolumn{3}{|c|}{ Variety: PKM 1} & \multicolumn{2}{|c|}{$\begin{array}{l}\text { Temperature } \\
\left({ }^{\circ} \mathrm{C}\right)\end{array}$} & \multicolumn{2}{|c|}{$\begin{array}{l}\text { Relative } \\
\text { Humidity (\%) }\end{array}$} & \multirow{2}{*}{$\begin{array}{c}\text { Rainfal } \\
(\mathrm{mm})\end{array}$} \\
\hline & $\begin{array}{c}\text { B. } \\
\text { caryeae }\end{array}$ & $\begin{array}{c}B . \\
\text { dorsalis } \\
\end{array}$ & $\begin{array}{c}B . \\
\text { correcta }\end{array}$ & $\begin{array}{l}\text { Collective } \\
\text { Population }\end{array}$ & $\begin{array}{c}\text { B. } \\
\text { caryeae }\end{array}$ & $\begin{array}{c}B . \\
\text { dorsalis }\end{array}$ & $\begin{array}{l}\text { Collective } \\
\text { Population }\end{array}$ & Max. & Min. & Mor. & Eve. & \\
\hline May 17 & 4.60 & 8.40 & 4.00 & 17.00 & 8.40 & 6.00 & 14.40 & 39.06 & 27.62 & 70.14 & 44.02 & 0.58 \\
\hline June & 6.00 & 1.75 & 1.75 & 9.50 & 7.75 & 3.25 & 11.00 & 38.43 & 27.48 & 64.35 & 37.50 & 0.08 \\
\hline July & 6.60 & 5.40 & 3.60 & 15.60 & 5.00 & 3.40 & 8.40 & 38.14 & 27.72 & 66.26 & 38.18 & 1.28 \\
\hline August & 26.75 & 20.50 & 9.25 & 56.50 & 25.25 & 15.25 & 40.50 & 35.48 & 25.85 & 76.45 & 45.05 & 5.65 \\
\hline September & 24.00 & 21.75 & 11.75 & 57.50 & 19.75 & 10.00 & 29.75 & 34.88 & 24.65 & 83.23 & 49.23 & 6.68 \\
\hline October & 3.50 & 2.25 & 0.50 & 6.25 & 7.25 & 6.25 & 13.50 & 34.55 & 24.95 & 85.93 & 56.95 & 3.45 \\
\hline November & 1.56 & 2.80 & 2.20 & 6.56 & 7.60 & 3.00 & 10.60 & 31.28 & 23.54 & 90.98 & 70.52 & 1.20 \\
\hline December 17 & 0.18 & 2.00 & 1.50 & 3.68 & 3.50 & 1.75 & 5.25 & 30.25 & 22.63 & 82.90 & 63.18 & 0.18 \\
\hline January 18 & 0.33 & 2.75 & 3.50 & 6.58 & 7.50 & 1.50 & 9.00 & 31.23 & 19.48 & 90.70 & 56.98 & 0.33 \\
\hline February & 0.00 & 1.00 & 1.50 & 2.50 & 3.00 & 1.00 & 4.00 & 32.34 & 20.12 & 87.08 & 46.24 & 0.00 \\
\hline March & 0.00 & 2.60 & 5.40 & 8.00 & 10.80 & 2.60 & 13.40 & 34.43 & 23.83 & 83.25 & 48.58 & 0.00 \\
\hline April 18 & 5.00 & 7.50 & 12.00 & 24.50 & 30.50 & 6.25 & 36.75 & 38.30 & 26.90 & 81.85 & 43.25 & 0.00 \\
\hline
\end{tabular}

* Averages of Standard Meteorological Weeks (SMW) comes in respective months.

Table 2: Correlation of weather parameters with the trap catch of fruit flies in Rumani variety of mango

\begin{tabular}{lllll}
\hline Parameters & B.caryeae & B. dorsalis & B. correcta & Total \\
\hline Temperature (Max.) & 0.038 & 0.112 & 0.130 & 0.253 \\
Temperature (Min.) & 0.127 & 0.171 & 0.163 & 0.264 \\
RH (Morning) & -0.115 & -0.019 & -0.045 & -0.157 \\
RH (Evening) & -0.100 & -0.065 & -0.161 & -0.231 \\
Rainfall & -0.154 & $-0.407^{* *}$ & -0.163 & -0.224 \\
\hline
\end{tabular}

${ }^{*}$ Correlation is significant at 0.01 per cent levels.

mentioned and strengthen the maximum activity of this Bactrocera spp. observed in the months of April, August and September in mango orchards.

\section{Impact of weather factors}

The correlation studies clearly shows that all the trap catches were positively correlated with the maximum and minimum temperature. Whereas, the morning $\mathrm{RH}$, evening $\mathrm{RH}$ and rainfall seems to be negatively correlated with the trap catches. The overall trap catches in rumani variety shows the positive correlation (Table 2) with the maximum temperature (0.253) and minimum temperature (0.264). The morning $\mathrm{RH}(-0.157)$, evening $\mathrm{RH}$ $(-0.231)$ and rainfall $(-0.224)$ shows the negative correlation. The trapped population of B.dorsalis showed the negative correlation with the rainfall $(-0.407)$. In case of PKM 1 the overall correlation reveals that positive correlation with maximum temperature (0.260) and minimum temperature (0.328), in contradict it shows (Table 3 ) negative correlation with morning RH (-0.153), evening $\mathrm{RH}(-0.169)$ and rainfall $(-0.410)$ at the mean time B.dorsalis shows the maximum negative correlation with the rainfall $(-0.434)$. The fruit flies are active throughout the year in southern parts of India, especially when the minimum temperature surges in summer (Verghese and Sudhadevi 1998).

The influence of weather parameters on the population of fruit fly should be studied to take 
Table 3: Correlation of weather parameters with the trap catch of fruit flies in PKM 1 variety of mango

\begin{tabular}{llll}
\hline Parameters & B.caryeae & B. dorsalis & Total \\
\hline Temperature (Max.) & 0.244 & 0.271 & 0.260 \\
Temperature (Min.) & 0.313 & 0.337 & 0.328 \\
RH (Morning) & -0.154 & -0.148 & -0.153 \\
RH (Evening) & -0.167 & -0.168 & -0.169 \\
Rainfall & -0.378 & $-0.434^{* *}$ & -0.410 \\
\hline
\end{tabular}

${ }^{* *}$ Correlation is significant at 0.01 per cent levels.

necessary precautionary measures for managing the pests (Kapoor 1993). The correlation results of trap catches with the weather parameter shows positive correlation with the maximum and minimum temperatures which is in corroboration with the findings of Patel et al. (2013). Whereas, the findings of Das et al. (2017) revealed that maximum temperature only positively correlated and minimum temperature shown negative correlation. The correlation of trap catches with relative humidity and rainfall shows negative correlation which was found to be in accordance with the report of Khan and Naveed (2017) and Kannan (2015), they have mentioned the same kind of statistical correlation in mango and guava ecosystem on varied species complex in Pakistan and Tirupathi regions.

\section{CONCLUSION}

The present investigation on the species diversity, distribution and varietal preference of fruit flies in mango ecosystem showed that the prevalence of three major species of fruit fly viz., B. dorsalis, $B$. caryeae and $B$. correcta and its activity was more during the hot summer and less during the winter season. The correlation study on influence of weather parameters also depicted the same, the fruit fly activities were highly positive in multiplication and dispersal on maximum and minimum temperature and negative impact towards the relative humidity and rainfall. The most important effective insect pest management involves the complete understanding of its behavioral nature with its existing environmental system. Hence, it is very much imperative and necessary to understand the environmental interaction with the fruit fly activity for the development and timely implementation of suitable organic or behavioral management technologies.

\section{ACKNOWLEDGEMENTS}

The corresponding author is greatly thankful to the Dean, Horticultural College and Research Institute for women, TNAU, Tiruchirappalli, for issuing the permission to take up the field experiment in mango orchard and M/s. sun agro biotech research centre, Mugalivakkam, Chennai, Tamil Nadu, for their material support by supplying the traps and lures.

\section{REFERENCES}

Agarwal, M.L. and Sueyoshi, M. 2005. Catalogue of Indian fruit flies (Diptera: Tephritidae). Oriental Insects, 39(1): 371-433.

Baloda, S., Sharma, J.R., Kumar, M., Singh, S. and Malik, A. 2018. Studies on performance of rejuvenated plants and fresh plants of guava, Int. J. Pure App. Biosci, 6(1): 939-941.

Das, U., Okram, S. and Jha, SKKS. 2017. Species diversity and monitoring of population dynamics of two species of Bactrocera (B. dorsalis, B. zonata) through methyl eugenol traps at lower gangetic alluvium of West Bengal. Journal of Entomology and Zoology Studies, 5(4): 372-376.

Kannan, M. 2015. Ecological studies on mango fruit fly, Bactrocera dorsalis Hendel. Ann. Pl. Protec. Sci., 14(2): 340- 342.

Kapoor, V.C. 1993. Indian Fruit Flies (Insecta: Diptera: Tephritidae). Oxford \& IBH Publishing Company Pvt. Ltd., New Delhi, pp.1-228.

Khan, R.A. and Naveed, M. 2017. Occurrence and seasonal abundance of fruit fly, Bactrocera zonata Saunders (Diptera: Tephritidae) in relation to meteorological factors. Pakistan Journal of Zoology, 49(3): 999-1003.

Kumar, U., Prasad, C.S., Vaibhav, V. and Saran, S. 2018. Population dynamics of mango fruit fly species caught through methyl eugenol traps at different locations of Western plain zone of Uttar Pradesh. Journal of Pharmacognosy and Phytochemistry, 7(2): 2167-2168.

Laskar, N. and Chatterjee, H. 2010. The effect of meteorological factors on the population dynamics of melon fly, Bactrocera cucurbitae Coq. (Diptera: Tephritidae) in the foot hills of Himalaya. Journal of Applied Sciences and Environmental Management. 14(3): 53-58.

Nair, N. and Bhattacharjee, T. 2017. Species composition of dacine fruit flies (Diptera: Tephritidae : Dacinae : Dacini) 


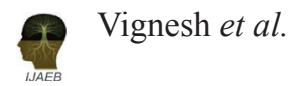

associated with cucurbits in Tripura, a north eastern state of India. Journal of entomology and zoology studies, 5(3): 330-335.

Patel, K.B., Saxena, S.P. and Patel, K.M. 2013. Fluctuation of fruit fly oriented damage in mango in relation to major abiotic factors. Hort. Flora Research Spectrum, 2: 197-201.

Rattanapun, W. Amornsak, W. and Clarke, A.R. 2009. Bactrocera dorsalis preference and performance on two mango varieties at three stages of ripeness. Entomologia Experimentalis Applicata, 131(3): 243-253.

Siddiq, M., Brecht, J.K. and Sidhu, J.S. 2017. Handbook of Mango Fruit: Production, Post-harvest Science, Processing Technology and Nutrition. John Wiley \& Sons. New Jersey, US, pp. 364.

Singh, S.P., Adarsha, L.K., Nandi, A.K. and Jopir, O. 2018. Production Performance of Fresh Mango in India: A Growth and Variability Analysis, Int. J. Pure App. Biosci., 6(2): 935-941.

Stanley, J., Gupta, J.P. and Rai, D. 2015. Population dynamics of fruit flies, Bactrocera spp. in North Western Himalaya. Indian Journal of Entomology. 77(3): 21-220.

Tan, K.H. and Seriti, M. 1994. Adult population dynamics of Bactrocera dorsalis (Diptera: Tephritidae) in Relation to host phenology and weather in two villages of Penang Island, Malaysia. Environ. Entomol., 23(2): 267-275.
Veeresh, G.K. 1989. Pest problems in mango; world situation. Acta. Horti., 2(231): 551-565.

Verghese, A. and Sudha Devi, K. 1998. Relationship between trap catches of Bactrocera dorsalis Hendel and abiotic factors. Proceedings of National Symposium on Pest Management in Horticultual Crops, In: Advances in IPM for Horticultural Crops (Eds. P.P. Reddy, N.K. Krishnakumar and A. Verghese), Association for Advancement of Pest Management in Horticultural Ecosystems, Bangalore, pp.15-18.

Verghese, A. and Jayanthi, P.D.K. 2001. Integrated pest management in fruits. In: Pest Management in Horticultural Ecosystems, Ed. Parvatha Reddy, P., Verghese, A., and Krishna Kumar, N.K., Capital Publishing Company, New Delhi, pp.1-23.

Verghese, A., Nagaraju, D.K., Madhura, H.S., Jayanthi, P.D.K. and Devi, K.S. 2006. Wind speed as an independent variables to forecast the trap catch of the fruit fly (Bactrocera dorsalis). Indian Journal of Agricultural Sciences. 76: $172-175$. 